\title{
An empirical study of lecturers' appropriation of social technologies for higher education
}

\author{
Suraya Hamid \\ University of Malaya, Malaysia \\ Jenny Waycott, Sherah Kurnia, Shanton Chang \\ The University of Melbourne, Australia
}

\begin{abstract}
The use of Online Social Networking (OSN) educational activities has become commonplace in today's higher education. OSN enables lecturers and students to generate and share content, interact, and collaborate in the knowledge construction process. The pedagogical benefits of social technologies have been widely discussed. However, less is known about the processes that lecturers follow when integrating social technologies into their teaching activities. With the aim of developing a practical guiding framework, this paper examines the processes that lecturers have followed when appropriating social technologies for learning purposes. Based on interviews with fourteen Australian lecturers and sixteen Malaysian lecturers who have used social technologies, different processes of appropriation are explored. Drawing on the empirical findings, this paper proposes a framework that can be used to guide lecturers in appropriating social technologies systematically. The framework will be beneficial for lecturers seeking guidance to support the appropriation of social technologies for structured and formal use in higher education.
\end{abstract}

\section{Introduction}

Online social networking (OSN) activities are becoming more prevalent in higher education around the world (Hughes, 2009; Kear, Woodthorpe, Robertson, \& Hutchinson, 2010; Mason \& Rennie, 2008). Social technologies enable OSN to be used in a range of educational activities (Hamid, Chang, \& Kurnia, 2009). Social technologies of interest in this paper include blogs, microblogs, wikis, social networking sites, video sharing sites and online discussion boards or forums. Because many social technologies were not originally designed for educational purposes, they need to be 'appropriated' or 'adapted' so they can be used effectively in higher education to enhance teaching and learning (Hemmi, Bayne, \& Land, 2009).

The driving factors for adoption of OSN include the increasingly ubiquitous access, ease of use, functionality, and flexibility of social technologies (Brown, 2010; Schroeder, Minocha, \& Schneider, 2010). It has been argued that social technologies can support social constructivist approaches to learning, since they have the potential to extend students' construction of knowledge and promote student interaction (Ferdig, 2007; McLoughlin \& Lee, 2008; Schroeder, et al., 2010). A further benefit of online social technologies is that they are often available at no cost or require marginal investment, hence removing a potential barrier to adoption (Brown, 2010).

While much has been written about why lecturers might want to use social technologies to support their teaching, less is known about how they go about appropriating social technologies for classroom activities. This paper aims to explore in detail the processes that lecturers follow when appropriating social technologies for learning purposes, and to develop a practical guiding framework to assist lecturers who wish to implement social technologies in their teaching. To achieve this aim, we conducted face-toface semi-structured interviews with thirty lecturers who are using social technologies for educational purposes in Malaysia and Australia. The research question addressed is: "How are social technologies appropriated for OSN educational activities?”

This paper is organised as follows. The next section presents a review of the literature covering the use of OSN in higher education, its benefits and challenges, and the research gaps concerning the appropriation of social technologies for educational purposes. This is followed by a description of the research methods employed for the study. We then present a framework of appropriation, illustrated with key findings that demonstrate the processes lecturers followed when appropriating social technologies for use in higher 
education. The paper concludes with a discussion of how this framework provides guidance for following a systematic approach for appropriating social technologies in higher education.

\section{Literature Review}

In the last few years, there has been much discussion about the use of social technologies in higher education (Bayne \& Ross, 2007; Hemmi, Bayne, \& Land, 2009; Shaohua \& Peilin, 2008; Zakaria, Watson, \& Edwards, 2010). This is illustrated through published examples of successful uses of social technologies in the extant literature (Ajjan \& Hartshorne, 2008; Dale \& Pymm, 2009; Hemmi, et al., 2009). It is widely believed that social technologies have the technological and educational capabilities to support teaching and learning (Augustsson, 2010; McLoughlin \& Lee, 2007). Social technologies enable social awareness and facilitate interpersonal interaction, thus providing justification for adoption of these technologies in higher education (Tay \& Allen, 2011; Thongmak, 2011; Yoder \& Stutzman, 2011).

The increasingly ubiquitous access, ease of use, functionality, and flexibility of social technologies have made them appealing as flexible learning tools to be adopted in higher education (Brown, 2010; Schroeder, et al., 2010). Social technologies are said to support active and social learning by providing environments that foster social interactions (Augustsson, 2010; Ferdig, 2007; McLoughlin \& Lee, 2007). Some authors have suggested that social technologies support constructivist approaches to learning and have the potential to socialise online learning to a greater extent than previously seen in traditional learning environments (McLoughlin \& Lee, 2008; Schroeder, et al., 2010). Social technologies allow for easy publication, sharing of ideas and re-use of study content, and commentaries. They also support links to relevant resources in information environments that are managed by the students and lecturers themselves (Brown, 2010; Kaplan \& Haenlein, 2010).

From the lecturers' perspective, the use of OSN educational activities can encourage online discussion amongst their students outside school, beyond the traditional classroom setting (Gray, Chang, \& Kennedy, 2010). In the case of social networking sites (SNS), students may personalise their respective pages by providing certain information such as their full name, year of birth, place of birth, educational background, hobbies and other information. Academics using these technologies in their classroom will then be able to learn more about the students they teach by simply viewing the students' profiles (Griffith \& Liyanage, 2008). Some social technologies such as wikis and to some extent blogs, encourage collaborative activities amongst students for the production of course assignments. This flexibility allows for active participation and therefore effective learning by students (Ajjan \& Hartshorne, 2008; AlaMutka, 2010). The collaborative production of work via social technologies can extend to other outcomes such as sharing and publishing the artefacts (e.g. course notes, assignments, test cases) produced as a result of the learning activity and inviting reflection and feedback from peers. Therefore, the use of OSN for higher education has the potential to enhance the teaching and learning experiences of both lecturers and students.

While the benefits of OSN in higher education have been widely discussed, little has been said about how lecturers go about appropriating social technologies for OSN educational activities. Since social technologies are typically not designed for educational purposes, how they are appropriated can significantly influence the benefits that lecturers and students obtain from their use for teaching and learning. It is therefore important to gain some understanding about the processes lecturers follow when appropriating social technologies for use in higher education. Although appropriation of social technologies in higher education has received limited attention, researchers have examined and defined technology appropriation in other contexts. Orlikowski (2000) viewed appropriation as 'technologies-inpractice' in the context of IT use in organisations. Similarly, Waycott (2004) examined appropriation as the integration of new tools into user's activities in both learning and workplace settings. Jones and Twidale (2005) argued that there are two types of appropriation: (a) serendipitous appropriation which includes the uses that arise out of spontaneity, and (b) goal-oriented appropriation, where a user finds a technology that can help him or her satisfy a need or aid in attaining a specific, defined goal (Jones \& Twidale, 2005). In the context of education, technology appropriation involves leveraging the affordances of new technologies to enhance teaching and learning (Ryan \& Lloyd, 2003). For Ryan and Lloyd, modern teaching involves having the courage and foresight to appropriate existing technologies to achieve teaching and learning goals. 
Reimer and Johnston (2012) argued that for technologies including social networking tools to be harnessed effectively, users need to explore, experiment with, and figure out how to place these technologies within their work practices. This exploratory and experimental approach, however, is not always suitable, particularly when there are many stakeholders who will be affected by how new technologies are used, as is the case in higher education (Gray et al, 2012). Researchers have stated that the appropriation of social technologies in higher education is not an easy, clear and straightforward process (Hemmi, et al., 2009; Kennedy et al., 2009). However, there appear to be no guidelines showing how social technologies should be appropriated for use in higher education, or by whom they should be appropriated. By understanding how social technologies are appropriated, lecturers who are yet to use OSN educational activities could better understand and adopt the approach most suitable to their needs.

To date, research into the use of social technologies in higher education has primarily focused on understanding students' experiences and identifying the potential learning benefits that social technologies provide in educational settings (Augustsson, 2010; Tay \& Allen, 2011). The recent studies that have examined lecturers' experiences have primarily focused on lecturers' reflections about the outcomes of using social technologies in higher education, rather than the processes by which lecturers appropriated those technologies for use in formal education (Waycott, Sheard, Thompson \& Clerehan, 2013; Gray et al., 2012). There is little in the current literature to guide lecturers through the appropriation process. Our study aims to address this gap by gaining insight into the processes lecturers have followed when appropriating social technologies to build their OSN educational activities. The methodology used to examine these processes is discussed below.

\section{Methodology}

This research adopted an interpretive and exploratory approach, deemed suitable for researching new phenomena and environments that are not well understood (Klein \& Myers, 1999; Walsham, 1995; Yin, 1994). The use of social technologies in higher education is a relatively recent phenomenon. An interpretive and exploratory approach was therefore required to understand the process of social technologies' appropriation, by engaging the people who are involved in OSN use in higher education.

\section{Data Collection}

This study employed a semi-structured interview technique. Face-to-face interviews were conducted with lecturers in Malaysia and Australia. In Malaysia, 16 lecturers from 9 public and private universities were interviewed in July and December 2010. A further 14 lecturers from 6 different universities in Victoria, Australia were interviewed from October to December 2011. In total, 30 lecturers from 15 universities were interviewed.

After obtaining University Ethics Committee approval, the lead researcher emailed selected lecturers with an invitation to participate in the research. Lecturers were identified through their university websites and their published academic papers about OSN, as well as through personal contacts. The duration of interviews was between 40 minutes to 1 hour. The participants were asked background information, followed by questions relating to their awareness and personal use of social technologies. Participants were then requested to share their reasons for using any particular social technology for OSN activities. They were also asked about the processes involved in the appropriation of social technologies for OSN activities. Lastly, participants were asked to describe the benefits, issues and opportunities of using social technologies to support teaching and learning.

For practical reasons, the research was conducted in the context of both Malaysia and Australia. The research was carried out in an Australian university and, as OSN use is a common practice by some lecturers in Australian universities, the Australian context was included in the research. The Malaysian context was included because the principal author is Malaysian and is familiar with the culture, social values, language and the overall educational context of Malaysia. This enabled the researcher to engage and establish strong associations with the research participants. It also provided access to a larger number of potential participants because of the first authors' established professional contacts. Conducting the research in both countries offered a good opportunity to explore the phenomenon more widely which, to a certain extent, improves the generalisability of the findings. Additionally, two-country data collection 
provides a broad data set that covers a range of settings within two different higher education systems. However, the cultural differences between the two countries are beyond the scope of this article.

The social technologies used, and the research participants' demographic information, is shown in Tables 1 and 2 below. The participants are quoted anonymously, using identification codes (e.g., M01 to represent first participant from Malaysia and A01 to represent first participant from Australia). Both tables show a good mix of participants in terms of gender, discipline, age, and social technologies used.

Table 1

Demographic information of lecturers from Malaysia

\begin{tabular}{lclcl}
\hline ID & Gender & Discipline & Age range & Social Technologies Used \\
\hline M01 & F & Education & $>45$ & Blog, Facebook \\
M02 & F & Education & $>45$ & Blog, Facebook \\
M03 & M & Eng \& IT & $25-35$ & Facebook, Twitter \\
M04 & F & Eng \& IT & $25-35$ & Facebook, Yahoo Messenger \\
M05 & F & Eng \& IT & $25-35$ & Facebook \\
M06 & F & Eng \& IT & $25-35$ & Online Discussion Forum (ODF) \\
M07 & F & Social Science & $>45$ & Facebook, Windows Live, Google Site \\
M08 & M & Eng \& IT & Above 45 & Facebook \\
M09 & M & Eng \& IT & $25-35$ & Twitter, Facebook, Google Docs \\
M10 & M & Eng \& IT & $36-45$ & Facebook, Twitter \\
M11 & F & Social Science & $>45$ & Facebook \\
M12 & F & Education & $>45$ & Blog, Facebook \\
M13 & F & Education & $>45$ & ODF, Facebook \\
M14 & M & Eng \& IT & $25-35$ & Facebook \\
M15 & F & Eng \& IT & $<25$ & Facebook \\
M16 & M & Education & $>45$ & Blog, ODF, Facebook \\
\hline
\end{tabular}

Table 2

Demographic information of lecturers from Australia

\begin{tabular}{lclcl}
\hline ID & Gender & Discipline & Age range & Social Technologies Used \\
\hline A01 & M & Medical Science & $>45$ & Wiki \\
A02 & F & Media \& Comm. & $>45$ & Blogs \& SecondLife \\
A03 & F & Education & $36-45$ & Blog \& Online Discussion Forum \\
A04 & F & Education & $36-45$ & Online Discussion Forum \\
A05 & F & Social Science & $25-35$ & Bebo \& Blog \\
A06 & M & Social Science & $>45$ & RenRen \& SecondLife \\
A07 & M & Social Science & $25-35$ & Blog \\
A08 & F & Media \& Comm. & $25-35$ & Flickr \\
A09 & M & Business & $>45$ & Blog, Wiki, RSS, Twitter \& Google Wave \\
A10 & M & Social Science & $25-35$ & Wiki \& Online Discussion Forum \\
A11 & F & Business & $>45$ & Skype, Moodle, Wiki, Podcasting, Blog, \\
A12 & F & Education & $36-45$ & Skype \& Podcast \\
A13 & M & Education & $>45$ & Blog \&Wiki \\
A14 & F & Business & $>45$ & Online Discussion Forum \\
\hline
\end{tabular}




\section{Data Analysis}

The data were analysed manually using thematic coding (Boyatzis, 1998). This involved careful reading of the transcripts, noting and comparing themes for coding, and transforming codes into categories. The data were analysed in accordance with guidelines for thematic coding of qualitative data (Creswell, 2003; Kvale, 1996).

All interview transcripts were printed, read multiple times, and notes were recorded in the margins to identify potential themes. These were then collated, reviewed, and examined for connections and redundancies. Over the course of the examination, the themes were expanded, contrasted and changed as more transcripts were analysed. The coding process resulted in themes reflecting the distinct appropriation processes undertaken by the lecturers. The themes were regrouped into three appropriation stages: planning, managing, and assessing. To mitigate potential subjectivity bias and to provide triangulation, the data analyses were reviewed by multiple researchers involved in this study. Based on the understanding obtained from the data regarding how the study participants appropriated certain social technologies, a general framework was developed that captures the key activities identified from the empirical study.

\section{Research Findings}

This section presents the framework, developed based on the empirical study, and provides a high level view of the appropriation process lecturers may consider when embedding a particular social technology in their teaching. The process is then illustrated in more detail by providing evidence from the empirical study.

\section{The Proposed Framework}

Based on the rich interview data and deep exploration of how the study participants appropriated social technologies for their teaching activities, 15 activities were identified as contributing to the overall process of appropriating social technologies for teaching and learning purposes. Figure 1 shows the proposed framework, with the 15 activities grouped into three stages.

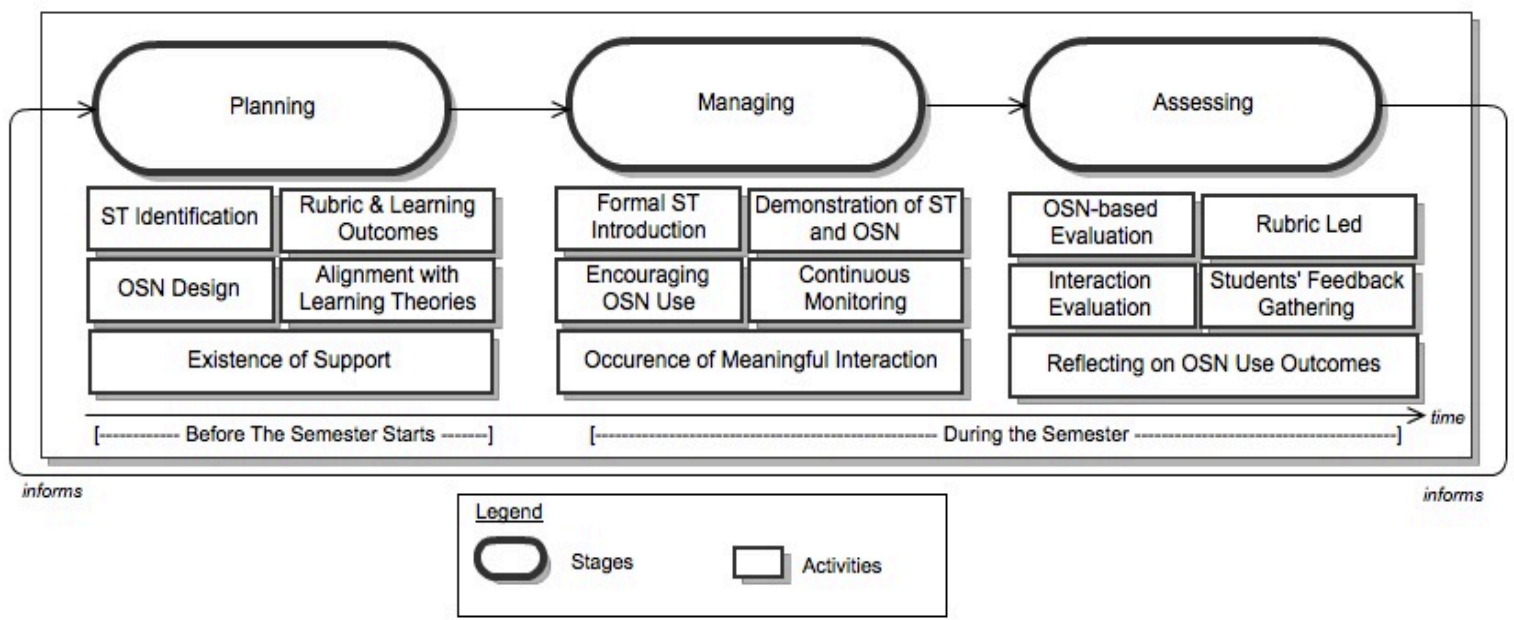

Figure 1. Framework of social technologies appropriation for OSN educational activities

According to this framework, the appropriation of social technologies can be conceived as a structured and cyclical process that follows the logical sequence of planning, managing, and assessing. The assessment stage then informs the next iteration of the OSN activity. Evidence was found that many lecturers typically engaged in many, or all, of these activities at each stage of the appropriation process, while some lecturers followed a more ad hoc approach. As argued below, the structured process is more 
valuable as a guiding framework, particularly for informing the appropriation of social technologies in formal education.

\section{Planning}

During the planning stage, lecturers performed one or more of the following activities: (i) identifying social technology platforms; (ii) developing a rubric for learning outcomes; (iii) designing OSN educational activities; (iv) aligning activity with learning theories; and (v) using existing support resources.

Identifying social technology platform

Interviewees used a number of strategies when identifying suitable social technology platforms. For example, they tried the technology themselves, read about it, or researched how it had been used in other educational settings. The identification process involved making sure that the platform could help students in achieving the course outcomes. One lecturer described how she went about testing suitable social technologies:

I spent a large amount of time testing a variety of websites and social technologies for their ease of use, privacy settings, and for their resemblance to the kinds of environments students would be likely to encounter outside of academia. If possible, my use of social technologies should cater to what the students would expect to also use outside of the educational setting. (A05)

The same lecturer took the initiative to attend conferences and workshops to add new insights about OSN for educational activities:

I also attended a few conferences and workshops to view first hand how others in the field were using OSN and other forms of computer-mediated communications in language teaching and other areas of education. Based on the insights from attending those conferences, I decided to keep using Bebo for my own class. (A05)

A Malaysian lecturer conducted a SWOT (Strengths, Weaknesses, Opportunities, and Threats) analysis in order to choose the right social technology for her class. She stated:

When I started using social technologies, what I did was compare at least two social technologies side by side. In addition to paper-based SWOT analysis, I also test-drive the social technologies to assess the social technologies' usability. For example, I once tried using Friendster with my students but it did not last long as we know, Friendster is no longer there. Besides, it cannot be used to systematically upload content and as a useful class information sharing. (M01)

Another lecturer emphasised the importance of identifying and choosing the right social technology:

Each and every social technology has its own strengths and weaknesses. Before we use it in the classroom, we need to find the right tool for the right students to the right information and to the right OSN activity. I think if you don't understand the philosophy and the rationales behind each social technology, it would not make any sense for you to proceed on. (M02)

Other lecturers were more casual in their selection of social technologies. For example, one lecturer considered his use of a wiki to be more experimental:

I am using Wiki and I think my way of using it is more experimental. Because of that, I don't have a clear process of identifying and then appropriating it. It just sort of happened and we used it for the class activities. (A10) 
Developing a rubric for learning outcomes

During the planning stage, some lecturers developed an assessment rubric intended to guide the students to achieve the learning outcomes. The importance of having a rubric was mentioned by a number of lecturers. Typically, the rubric would contain the week-by-week activities, the assessment associated for the week(s), how the assessment would be evaluated in detail as well as how the marks would be allocated. The analysis revealed there were 13 lecturers from Australia and 7 Malaysian lecturers who claimed to have an OSN course rubric. One lecturer said she had a set of criteria for her students when they used a blog:

I provide my students with the assessment criteria for the blogging tasks. So, it is not just simply about writing reflection. I set the criteria for what needs to be in the students' blog entries. (A04)

Another lecturer said that he allocated 5\% of marks for students to do a peer review:

My course assessment is not solely on interaction but on other criteria. They are stated in the course rubric. However there is a week where we get students to form a peer review and mark each other's wikis. We give them $5 \%$ of the overall mark for the quality of their comments on other people's wikis. (A01)

One of the lecturers who did not prepare the OSN assessment rubric mentioned the importance of a having such a rubric:

Yes, sometimes students came to me saying they were unclear of how to do things. And I gave them my advice based on what I expected. But yes, for my course, there was no rubric on how the students should use the social technologies. It would be good if I have one. (A09)

\section{Designing OSN educational activities}

Examples of OSN activities included content generating, sharing, interacting, and collaborating. When designing OSN activities, lecturers considered the pedagogical rationale and matching the technology to the intended learning outcomes of the course:

There are two aspects to that (designing). One aspect I look at is the content, the topics and key challenges within the course I will be teaching and maybe match up the social technology that I think could illustrate that particular concept ... so, in this regard, we could say that the pedagogy is motivating the technology use.(A12)

In designing OSN educational activities, lecturers evaluated the key strengths of the social technologies, which they matched to the intended learning outcomes. For example, wikis were selected for collaboration-based activities:

For the Wiki, specifically I design Wiki for their collaborative group work ... they will be doing it better inside Wiki ... I don't find it quite convenient to do it in Facebook or Twitter. (M10)

Similarly, another lecturer described how he designed an OSN activity using the virtual world platform SecondLife, which incorporated problem solving as a key element:

Our lessons are first based on constructivist principles. The lessons in SecondLife are taskbased and often involve some form of problem solving. Further, the designed activities enabled students to take the lead in their own learning, based on a range of topics and guidelines provided for them and are encouraged to support each other. (A06)

Aligning with learning theories

Lecturers aligned their appropriation of social technologies, and their design of OSN activities, to suit certain learning theories such as the social constructivist learning theory. Eight Malaysian lecturers and 
nine Australian lecturers were found to consider the alignment of designed OSN educational activities with the learning theories. Guided by social constructivism, the focus of teaching and learning shifts from a lecturer-centred to student-centred approach, in which students work in groups to construct their own knowledge. For those lecturers guided by this theory, the student-centred approach was applied and emphasised throughout the OSN activities:

When I designed my course, I was guided generally by the constructivist principles and self-directed learning. Students are expected to be developing an attitude to self-generation of knowledge and life-long learning partly through exploration of the social technologies. (A02)

The learning outcomes planned for the course were the main drivers for OSN adoption. For example, the following lecturer claimed:

In terms of specific steps, I guess I look at what I want to achieve pedagogically first, then try to match that with whatever social technologies or other platforms available out there. I also have to consider what the activities will bring to the learning experience that students are not already getting. (A06)

Using existing support resources

Lecturers often considered what support resources were available from the university when they planned to implement OSN. The support included technical assistance provided by the IT Unit, any relevant training, and the availability of tutors to help manage large classes. For example, one lecturer described working with educational designers to develop a wiki-based OSN activity:

I work with the educational media group at the university and they supported me in developing the wiki, which would enhance educational activities. (A01)

To reduce the workload issue, support from tutors in grading students' work was important, as mentioned by this lecturer:

In the first semester class, there would be about 100 students. In the second semester, I have about 80 students. It's a bit of work reviewing what they have done, but then we create rubrics to make it easy for myself and the tutors to mark and get consistency of marking. (A10)

In summary, lecturers engaged in various strategies to plan how they were to use social technologies in their teaching. These included identifying suitable social technology platforms, developing a rubric, designing OSN educational activities, aligning the OSN activities with learning theories, and using the existing support resources available to them from the university.

\section{Managing}

The appropriation process also required lecturers to manage the OSN activities over the course of the semester. The activities lecturers engaged in during this stage included: (i) formally introducing students to the social technology, (ii) demonstrating the social technology to students, (iii) encouraging students' used of OSN, (iv) continuous monitoring of OSN use, and (v) ensuring the occurrence of interactions.

Formally introduce students to social technology

In most situations, lecturers formally introduced the students to the social technology platform to be used for OSN educational activities. The majority of lecturers performed this practice (15 Malaysian lecturers and 11 Australian lecturers). Conversely, 1 lecturer in Malaysia and 3 lecturers in Australia introduced the social technologies informally by asking the students to explore the technologies on their own while doing the OSN educational activities. The formal introduction was typically made during the first lecture or teaching session at the start of the course, which was normally conducted face-to-face basis in a lecture hall or classroom, as this lecturer described: 
During the first week of the class, I would inform my students that we would use these tools to support the teaching and learning. I also told them that their work would be accessed as well assessed through their use of these social technologies. So during the first contact hours, I would brief them on all these three social technologies: Twitter, Wiki and Facebook. (M10)

During this initial class, lecturers also highlighted the course expectations and the learning objectives, and students were given the opportunity to ask questions about OSN. While some students appeared to have advanced knowledge about the social technologies, others needed further support. One lecturer implemented a drop-by session to provide this extra support:

Originally when we started the class, we had a computer lab session where students were given instruction, first of all, on how to type in the Japanese because it is quite complicated and then secondly how to use the Bebo to make a profile. We found that it was really too easy for a lot of our students. Most people could already make the profile and a lot of students, because they come from Chinese or Korean background, already understood how to use Asian typing because it's very similar to the different languages. But there are just some students who really struggle and still need that help. So what we have done now is we changed the process so that the students just come to a drop-by session. If they need help they can come, maybe just 1-6 people who come and everyone else just try by themselves. (A05)

\section{Demonstrating social technology}

In addition to introducing the social technologies, lecturers would normally demonstrate either individually or in groups, how the students should use the social technologies for the OSN educational activities. More than half of the total participants from both countries demonstrated the social technologies to their students in various ways, such as direct demonstration on the computers, or by showing exemplars from previous semesters. The demonstrations served the purpose of emphasising the value of using social technologies and to alleviate students' fears, if any. One of the lecturers stated:

In the beginning, probably about $20 \%$ of the students were reluctant to do the learning activities using social technologies. They don't think they can do it and worry about it. By stating the benefits and showing how it should be done, at least students would become more receptive to the idea of social technologies use. (A11)

Another lecturer who used the show-and-tell strategy demonstrated how the social technologies would be used for the course purposes. He also asked the students to experiment with the social technologies to give them a sense of familiarity with the tools:

I will allow the students to play around with the Wiki to get familiar with the tool. For example, in Wiki, I ask groups to introduce members of their group. They put in their profile, names, their area of specialisation, as well as their interest in becoming teachers, why do they want to take my course, sort of personal reflections within the group. (M10)

Encouraging students' use of OSN

A majority of lecturers in both countries (14 in Malaysia and 12 in Australia) mentioned that they persistently encouraged their students to use OSN throughout the semester. For example, one Malaysian participant claimed:

I ensure that I must reply to my students' comments, however minimal like by saying simple things like I noted your suggestions, thanks for your comment or more elaborate feedback such as I totally agree with your view. Further, if I may offer an alternative view to that initial thought of yours ..., that kind of thing. I think, these kinds of responses no matter how simple it is, would encourage the students to consistently use OSN. (M01)

According to the lecturer above, the comments would indicate to the students that she actually read and appreciated their replies. The lecturer also added that, if the students sent her a link to visit, she would 
make an attempt to do so and provide her own views about the materials shared by the students. By doing so, she believed the level of students' motivation would increase and they would be more engaged with the course.

\section{Continuous monitoring of OSN use}

Most lecturers described continuously monitoring their students' use of OSN with 13 Malaysian lecturers and 11 Australian lecturers engaged in this activity. By looking at the students' use of social technologies over time, lecturers could identify usage trends:

Interestingly, when I monitor the students' use of social technology for the class, it is like bell shape. At the beginning, there are some who are reluctant and slow to adopt it. But when you progressed to later weeks, the usage trend went up, very high. And those are the times when the traffic got very high. They participated and interacted. Then towards the end of the semester, there was a slowing down pattern as they are preparing for exams and etc. So it was like $10 \%$ in the beginning, $10 \%$ at the end, and the other $80 \%$ will be somewhere in the middle of the semester. (M16)

Monitoring students' consistent use of social technologies enabled the lecturers to make informed decisions on whether to intervene, such as by strongly enforcing the access and use of the social technologies, or just giving mild reminders to the students. When detecting students who were struggling to cope with the class, one lecturer said she would email the student personally and offer assistance:

If I have students that are clearly struggling and not following the criteria and not meeting the expectation, I email them privately and give them some strategies perhaps that they could use to improve their writing... Usually it comes down to lack of research ... Sometimes students post the thread out, just based on their mere opinion ... I said you have to move from mere opinion to informed opinion. (A03)

Another lecturer described a similar approach. By monitoring students' blog activities, feedback could be given to the students to encourage them to improve in their next blog posting or comment. In this way, continuous monitoring of students' OSN activities provided an opportunity for lecturers to provide formative feedback:

I also have a look at their blogs, I give them feedback... what I was looking for... whether they should be different focus, different things and putting more efforts on different aspects. (A09)

\section{Ensuring the occurrence of interactions}

While managing OSN activities, some lecturers employed specific strategies to ensure the occurrence of interactions among students. When monitoring students' OSN activities, the lecturers emphasised the importance of having constant interactions with each other as well as with the lecturers. This was done by monitoring students' comments on their peers' entries. Where necessary, the lecturer would also intervene and leave his or her own opinions:

I regularly monitored the blogs and left comments on students' blogs to ensure that the students did interact with each other. I also tried to leave at least one comment on each student's blog every few weeks, so they know I was paying attention to their contributions and discussion via OSN. (A07)

Another lecturer noted that some students required extra encouragement to engage in the interaction:

On Renren.com, some students were very active, interacting both among themselves and with users external to the course. Their interaction was very positive and they tended to encourage each other quite a bit. Some students did not really engage with the environment or the others in the environment, which may have been for a range of reasons including personality and language ability. So, I frequently motivate such students to participate 
minimally at first and try to increase their interaction when they become more confident. (A06)

\section{Assessing}

The third stage in social technology appropriation is assessing. This refers to both assessment of students' work and assessment of the OSN tasks as a learning activity. Generally, the assessments were embedded into various OSN educational activities and students were required to complete a particular task for assessment. The activities during the assessment stage included: (i) assessing students based on their OSN educational activities, (ii) use of rubric to guide students' OSN assessment, (iii) evaluation of students' interaction using OSN, (iv) gathering students' feedback, and (v) reflecting on OSN use outcome.

Assessing students based on OSN educational activities

Participating lecturers generally found it was important to assess their students' use of OSN. Nine Malaysian lecturers and thirteen Australian lecturers allocated marks for OSN-based coursework. The remaining lecturers did not assess their students' OSN educational activities. The reasons for assessing the students' OSN educational activities were to motivate and to reward the students. One of the Malaysian lecturers claimed:

If you ask me why I assess students' OSN activities, it is really simple. There is simply a direct correlation between that thing. If you ask them to do something without giving them the grades or rewards, there is no point for them to involve in that. Although they think it is beneficial for their studies, definitely they won't take any part in it if there is no assessment made for their OSN activities. (M10)

Some lecturers meticulously carried out assessments on a weekly basis, while others conducted formal assessments only at the end of the semester. The lecturers who consistently monitored their students' activities during the semester would look at the forums or the blog entries of the students in order to see whether the students were really working on their assignment or not. The timeliness of submission was given priority as highlighted by one of the lecturers:

We expect the students to make at least one post per week each (during Week 3 to Week 12) and to leave two to three comments on other students' blogs per week. Students who do less than this will not receive high marks and students who do less than five blog posts are very likely to fail. Blogs which show evidence of continuous and steady efforts throughout the semester will be rewarded with better marks, while those which are not updated regularly will be penalised or risked being failed. I typically notice a flurry of entries in the final week but this inconsistent blogging behaviour is not accepted, at least by me. (A07)

Some lecturers did not assess the students' OSN educational activities. Instead, the focus of assessment was on traditional assignments such as written coursework, presentations made to the classroom and examinations. One lecturer provided the following reasoning:

The students interact with me and their peers using other mediums for example text message, or face-to-face interactions but only very little using social technologies. So, it is pretty tough to assess students on their interaction using social technologies. I also prefer for them to have a more natural way of interacting. For assessment, mine is more conventional kind of assessment where I evaluate their assignments and examinations more than anything else. To me, their assignments and exams are sufficient to indicate what they have learned from the learning process and the associated learning activities. (A10)

One lecturer also noted that while assessment was a good way to measure the students' level of understanding of the course, what was more meaningful to him was that the students could carry on successfully in life using the skills and knowledge learnt from their OSN experience.

The social technology does not really matter. What is more important is that the technology enables the students to use their knowledge and skills in a practical and meaningful way 
and to learn beyond the boundaries of what we were doing in class. We just provide the students with the basic exposure to these technologies. Eventually, for anything that we do, we try to set students up with skills and knowledge that will free them from us as lecturers and empower them to go on learning and using their skill independently after they finish our course. By having the knowledge, we hope that they would have a life-long avenue for learning and using the skills they got from us. (A06)

Using rubric as the guide in assessing students

The importance of having a rubric was mentioned by 7 Malaysian lecturers and 12 Australian lecturers. Typically, the rubric would contain the week-by-week activities, the assessment associated for the week(s), how the assessment would be evaluated in detail as well as how the marks would be allocated, according to the quality of the submission. Generally, this activity reflects the actual use of the rubric developed during the "Planning" stage mentioned earlier.

My course assessments are stated in the course rubric. For example, in the rubric, there is a week where we get students to form a peer review and mark each other's wikis. We give them $5 \%$ of the overall mark for the quality of their comments on other people's wikis. By including that in the rubric, the students would be aware of what our expectations from them are. (A01)

Another lecturer said that the use of rubric is to ensure students are fully prepared for the assessment:

Basically there are no surprises. I provide the students with the assessment criteria with the blogging tasks. It is not just the blog or whatever you like ... there is a set criteria. They students know in advance how they are going to be assessed. (A04)

For those lecturers who followed an ad-hoc approach, the absence of a rubric-led assessment proved to be quite a challenge. One of these lecturers stated:

I checked the students' work like once or twice on the social technologies they were using, like blogs or wikis. Sometimes I tell them to do more if I see they are lacking in certain things. But the challenge is this: when the students asked me what is the expected answer or how do I assess their work, and what are the indications of good answers. I have problems there as I have no clearly spelt out rubric to help me and also to help the students! (A09)

\section{Evaluating students' interactions}

For some lecturers, student interaction was part of the overall course assessment. There were 9 Malaysian lecturers and 10 Australian lecturers who evaluated their students' interaction through OSN education activities. For example, one of the lecturers allocated $60 \%$ of the overall course marks on the assignments to OSN educational activities, with interaction among group members given emphasis in the assessment. The lecturer claimed:

I usually associate students' quality of work with their interaction level. If there is a high degree of interaction among students, I can see that their work is generally better than those who do work in isolation or not much interaction. Further, I allocate like $60 \%$ of the overall course marks on assignments that students work on OSN. (M10)

Another lecturer who assessed the students' interaction used the strategy of giving overall marks at the end of the semester. The lecturer claimed:

I assess my students' interaction and give them marks accordingly. But I don't give them weekly marks or weekly assessment. It is overall. So we need to know or they need to be aware that the discussion just not involves only one week ... but it is throughout the whole semester. So the whole assessment in interaction will be given at the end of the semester. (M13) 
Gathering students' feedback

Most lecturers implemented the activity of gathering students' feedback. All Malaysian lecturers and 12 Australian lecturers performed this activity. In most instances feedback was gathered at the end of the semester via a survey:

We did a survey at the end of every semester for the whole groups in this course. The survey findings were used as inputs and to learn how to make it a better practice in the future semesters. (A05)

Improvements made based on the previous semester's results indicated continuous enhancement to the course and the use of the social technologies. One lecturer described this iterative process as follows:

We evaluate the students' feedback every semester. Based on the responses, we are working together in this research group to improve the course. From there onwards, we sort of build our own expertise in this area (use of social technologies such as SecondLife in the classroom). (A12)

\section{Reflecting on OSN educational activities' outcomes}

The practice of evaluating and reflecting on their experience of using social technologies is something that differentiates the ad-hoc and systematic appropriation approaches. This reflection takes the form of sharing the appropriation process, the students' feedback, the benefits and challenges and other experiences with colleagues. The platform used for sharing experiences with colleagues could be in any knowledge sharing sessions, by giving training to other lecturers in workshops, presenting at conferences, as well as writing for journal publications. For example, the outcomes from the use of Bebo for teaching and learning foreign language were shared with the public through a number of academic papers by one of the lecturers:

The reflections made from our use of OSN was written in research papers. We also used the survey findings with lecturers as the data to produce several research papers presented in relevant conferences and journals. (A05)

This reflection and sharing of information with colleagues is an important component of the appropriation process, providing an opportunity to inform future uses of social technologies in higher education.

\section{Discussion}

The analysis of how lecturers appropriated social technologies for use in higher education revealed fifteen activities that lecturers engaged in during this appropriation process. Not all lecturers engaged in all 15 activities. Instead, there was evidence suggesting that social technologies were appropriated differently by different lecturers. Some lecturers were quite systematic in their approach, and followed most (if not all) of the identified activities. Others followed a more ad hoc approach. Their use typically involved informal and exploratory strategies, with little attention given to formally introducing the activity to students, or developing rubrics for assessment. In general, however, the lecturers did follow three main stages when appropriating social technologies for OSN educational activities, which map to the stages followed in the design and implementation of the majority of educational activities: 1) planning, 2) managing, and 3) assessing. These stages, and the 15 activities identified, are represented in the framework presented in Figure 1.

As discussed above, technology appropriation involves users integrating new technologies into activities and using tools in ways that are sometimes disparate from the uses the designers originally intended for the tools. When social technologies are used in higher education, some amount of appropriation is always required. Many social technologies were not originally designed for use in formal education, although their design emphasises collaboration and the sharing of user-created content, making them ideal as learning tools (McLoughlin \& Lee, 2007). Each educational setting where a new technology is used has particular learning objectives, involves a new group of students with particular motivations, and is taught by a lecturer drawing on his or her own teaching and learning experiences and underlying philosophies. In other words, each educational setting is unique, so lecturers must appropriate the technology to fit into the 
particular objectives and requirements of that setting. Evidence was found suggesting this is exactly what lecturers did, choosing to use specific social technologies in particular ways to create OSN educational activities that were a good match for the learning objectives of the course and the teacher's underlying pedagogy. This paper, however, focuses on appropriation processes, rather than pedagogy. It has not examined in detail the pedagogical rationale behind each lecturer's decision to use OSN in their teaching. It is important to note that this research was conducted in the context of pedagogical changes in higher education, which may explain why social technologies are gaining broad popularity as educational tools. The pedagogical rationale for the use of social technologies in educational settings has been widely discussed in the literature. However, although there are many case studies of OSN activities in higher education, the processes taken by lecturers in their appropriation of social technologies are still not well understood and therefore not easily replicated. Each time a lecturer wants to use social technologies in higher education, they have to reinvent the wheel. The aim of this paper is to explicate this process and provide guidance for lecturers who choose to appropriate social technologies for use in higher education in the future.

The findings provide support for Jones and Twidale's (2005) argument that there are two types of appropriation: serendipitous and goal-oriented appropriation. In many ways, the ad hoc process of appropriation that some of the interviewees followed could be labelled 'serendipitous', although there was still some planning involved in this form of appropriation. The decision to use social technologies in this setting did not emerge entirely spontaneously, and in all cases there was an ultimate goal to improve teaching and learning through the use of social technologies. There appear to be two forms of goaloriented appropriation: systematic and ad hoc. The framework presented in Figure 1 illustrates a systematic process of appropriation. This framework is intended to be used as a guide for lecturers to appropriate social technologies systematically. A systematic process of appropriation would help lecturers to have better control and management of their social technology use. While ad-hoc appropriation may be suitable for informal use (i.e., as an additional communication tool to support student interaction that is not part of the formal curriculum), it is proposed that systematic appropriation is best when using social technologies as a formal part of the curriculum. In this setting, ad hoc or informal processes of appropriation could disadvantage students, particularly when students are formally assessed for their OSN activities (Gray et al., 2012).

The proposed framework responds to the concerns by Kennedy et al. (2009) and Hemmi et al. (2009) regarding a lack of a clear and straightforward process of appropriation. The framework can be used as a checklist for lecturers wishing to appropriate social technologies for formal use in higher education. For example, lecturers with little experience of social technology appropriation would be able to quickly adopt social technologies in their teaching process using the framework as the basis of their checklist. Lecturers with wide exposure to social technologies might also find the framework useful as it encompasses comprehensive activities starting with planning and ending with the assessment stage. The feedback loop at the end of the assessing stage informs the overall experience throughout the semester to be considered and addressed in the next cycle of OSN use. The activities recommended in the assessing stage of the framework could be used as the starting point to overcome the reservation of other lecturers who may be uncertain about the idea of utilising social technology, and do not recognise its potential for facilitating the assessment of students' learning outcomes.

The framework is deliberately simple, as it is designed to be used in multiple settings by lecturers who are either novices or experienced at using social technologies in higher education. It is designed to be used as a checklist whereby it is a representation of the different stages and/or activities that lecturers should be aware of when planning to use social technologies in their teaching. Overall, the framework can be taken as a generic framework as it offers a sufficient level of detail and can be applied across all social technology platforms. Further, it was not meant to be prescriptive as lecturers need to be able to decide and be creative in the detailed aspects of their social technology appropriation. While lecturers are likely to be motivated by pedagogical concerns in their use/design of OSN activities, the pedagogical motivations for using OSN in higher education are not addressed in detail here. The framework is designed to be used across teaching and learning contexts, and pedagogical concerns are likely to be specific to the particular setting in which OSN activities are being implemented.

This framework of social technologies appropriation for OSN educational activities is arguably similar to the widely recognised ADDIE (Analyse-Design-Develop-Implement-Evaluate) model from the 
instructional design field, although it is different in a number of ways. Firstly, the ADDIE model is primarily used by instructional designers and training developers (Morrison, 2010; Peterson, 2003). In this research, the target users of the framework are the lecturers. Secondly, the ADDIE model is often used for building effective training and performance support tools (Peterson, 2003). In the current study, the framework aims to support effective appropriation of social technologies for OSN educational activities. Lastly, the ADDIE model is composed of five phases and focuses mainly on the analysis, design and development stage of the instructional design artefact or system. In this research, the first three stages of ADDIE are combined into one stage, called the planning stage. The proposed framework focuses on the planning aspect of the appropriation of social technology, while at the same time giving attention to the management and assessment components of the appropriation. This is similar to the cyclical and staged process recommended by Gray et al. (2012).

\section{Conclusion}

This paper has explored how lecturers appropriate social technologies for use as OSN educational activities in higher education. Based on interviews with 30 lecturers across two countries, our study provided empirical data illustrating a number of activities that lecturers engaged in when planning, managing, and assessing their use of social technologies in their teaching. These activities are presented in a framework that can be used as a checklist to guide lecturers in the future appropriation of social technologies in higher education. Such a framework is necessary, as there is little information in the existing literature to guide lecturers through this structured process of appropriation.

This research contributes to an understanding of teaching practice in higher education. The use of social technologies in higher education is still emerging. This nascent field requires more empirical investigation, and the results of this study contribute towards a better understanding of OSN use in higher education. This paper is not without limitation. The data were collected from two countries, which increased the breadth and richness of the data. However, the research involved a relatively small sample. One of the research limitations, therefore, is limited generalisability. Future studies are required to increase the sample size in order to make the findings more representative. Longitudinal and ethnographic approaches, where researchers spend significant amounts of time observing lecturers' and students' practices in appropriating and using OSN would also be valuable in providing richer insights. Nevertheless, this study has made a significant step towards gaining a better understanding of the processes that lecturers follow when appropriating social technologies for use in higher education, with a view to informing future practice in this area.

\section{Acknowledgements}

This research was financially supported by the University of Malaya and the Ministry of Higher Education, Malaysia, under research grant RG005E-13ICT.

\section{References}

Ajjan, H., \& Hartshorne, R. (2008). Investigating faculty decisions to adopt Web 2.0 technologies: Theory and empirical tests. Internet and Higher Education, 11, 71-80.

Ala-Mutka, K. (2010). Learning in informal online networks and communities. Seville, Spain: Institute for Prospective Technological Studies, European Commission.

Augustsson, G. (2010). Web 2.0, pedagogical support for reflexive and emotional social interaction among Swedish students. Internet and Higher Education, 13, 197-205.

Bayne, S., \& Ross, J. (2007). The 'digital native' and 'digital immigrant': a dangerous opposition. Paper presented at the Annual Conference of the Society for Research into Higher Education (SRHE)

Boyatzis, R. (1998). Transforming qualitative information: Thematic analysis and code development. SAGE Publications

Brown, S. (2010). From VLEs to learning webs: The implications of Web 2.0 for learning and teaching. Interactive Learning Environments, 18(1), 1-10.

Creswell, J. W. (2003). Research design: Qualitative, quantitative, and mixed methods approaches. Thousand Oaks, California, US: Sage Publications. 
Dale, C., \&Pymm, J. (2009). Podagogy - The iPod as a learning technology. Active Learning in Higher Education, 10(1), 84-96.

Ferdig, R. E. (2007). Editorial: Examining social software in teacher education. Journal of Technology and Teacher Education, 15(1), 5.

Gray, K., Chang, S., \& Kennedy, G. (2010). Use of social web technologies by international and domestic undergraduate students: Implications for internationalising learning and teaching in Australian universities. Technology Pedagogy and Education, 19(1), 31-46.

Gray, K., Waycott, J., Clerehan, R., Hamilton, M., Richardson, J., Sheard, J., \& Thompson, C. (2012).Worth it? Findings from a study of how academics assess students' Web 2.0 activities. Research in Learning Technology, 12(1).

Griffith, S., \&Liyanage, L. (2008). An introduction to the potential of social networking sites in education. Paper presented at the Proceedings of the Second Emerging Technologies Conference.

Hamid, S., Chang, S., \& Kurnia, S. (2009). Identifying the use of Online Social Networking (OSN) in higher education Paper presented at the Ascilite, Auckland, New Zealand.

Hemmi, A., Bayne, S., \& Land, R. (2009). The appropriation and repurposing of social technologies in higher education. Journal of Assisted Learning, 25(Special Issue), 19-30.

Hughes, A. (2009). Higher education in a Web 2.0 world.Report of an Independent Committee of Inquiry into the impact on higher education of students' widespread use of Web 2.0 technologies.UK.

Jones, M. C., \& Twidale, M. B. (2005). What's in a Name? Exploring the Connections between Abstraction and Appropriation. International Reports on Socio-Informatics 2(2), 43-47.

Kaplan, A. M., \&Haenlein, M. (2010). Users of the world, unite! The challenges and opportunities of social media.Business Horizons, 53, 59-68.

Kear, K., Woodthorpe, J., Robertson, S., \& Hutchison, M. (2010). From forums to wikis: Perspectives on tools for collaboration. Internet and Higher Education, 13, 218-225.

Kennedy, G., Dalgarno, B., Bennet, S., Gray, K., Waycott, J., \&Judd, T. (2009). Educating the Net Generation. A Handbook of Findings for Practice and Policy. California, USA: Creative Commons.

Klein, H. K., \& Myers, M. D. (1999). A set of principles for conducting and evaluating interpretative field studies in information systems.MIS Quarterly, 23(1), 67-94.

Kvale, S. (1996).Interviews: An introduction to qualitative research. Thousand Oaks: Sage Publications.

Lincoln, Y. S., \&Guba, E. G. (1985). Naturalistic inquiry. Beverly Hills, California: Sage Publications.

Mason, R., \&Rennie, F. (2008). E-Learning and social network handbook: Resources for higher education. Madison Ave, New York: Routledge.

McLoughlin, C., \& Lee, J. W. L. (2007). Social software and participatory learning: pedagogical choices with technology affordance in the Web 2.0 era. Paper presented at the Proceedings Ascilite Singapore 2007, Singapore.

McLoughlin, C., \& Lee, J. W. L. (2008). The three P's of pedagogy for the networked society: Personalization, participation, and productivity. International Journal of Teaching and Learning in Higher Education, 20(1), 10-27.

Morrison, G. (2010). Designing effective instruction(6th ed.). New Jersey: John Wiley \& Sons.

Opdenakker, R. (2006). Advantages and disadvantages of four interview techniques in qualitative research.Forum: Qualitative social research, 7(4), 11.

Orlikowski, W. J. (2000). Using Technology and Constituting Structures; A Practice Lens for Studying Technology in Organizations. Organization Science 11(4), 404-428.

Peterson, C. (2003). Bringing ADDIE to life: Instructional design at its best. Journal of Educational Multimedia and Hypermedia, 12(3), 227-241.

Reimer, K., \& Johnston, R. B. (2012). Place-making: A phenomenological theory of technology appropriation. International Conference on Information Systems, Orlando, USA, $19^{\text {th }}$ December 2012

Ryan, M., \& Lloyd, M. M. (2003) Online, off-line, teaching in between the lines. In OLT 2003 Excellence: making the connections, 5 November, 2003, Brisbane Convention \& Exhibition Centre

Schroeder, A., Minocha, S., \& Schneider, C. (2010). Social software in higher education: The diversity of applications and their contributions to students' learning experiences. Communications of the Association for Information Systems, 26, 547-564.

Shaohua, H., \& Peilin, W. (2008). Web 2.0 and social learning in a digital economy. Paper presented at the IEEE International Symposium on Knowledge Acquisition and Modeling Workshop, 2008. KAM Workshop 2008.

Tay, E., \& Allen, M. (2011). Designing social media into university learning: Technology of collaboration or collaboration for technology? Educational Media International, 48(3), 151-163. 
Thongmak, M. (2011). Facebook adoption as computer-mediated communication for university students. Paper presented at the AMCIS 2011 Conference Proceedings. Retrieved from http://aisel.aisnet.org/amcis2011_submissions/31

Walsham, G. (1995). Interpretive case studies in IS research: Nature and method. European Journal of Information Systems, 4, 74-81.

Waycott, J. (2004). The appropriation of as learning and workplace tools: An activity theory perspective.Milton Keynes, UK:The Open University..

Waycott, J., Sheard, J., Thompson, C., \&Clerehan, R. (2013). Making students' work visible on the social web: A blessing or a curse? Computers \& Education, 68, 86-95.

Yin, R. K. (1994).Case study research: Design and methods. Thousand Oaks, CA: Sage.

Yoder, C., \&Stutzman, F. (2011). Identifying social capital in the Facebook interface. Paper presented at the Conference on Human Factors in Computing Systems (CHI 2011).

Zakaria, M. H., Watson, J., \& Edwards, S. L. (2010). Investigating the use of Web 2.0 technology by Malaysian students. Multicultural Education \& Technology Journal, 4(1), 17-29.

Corresponding author: Suraya Hamid, suraya_hamid@um.edu.my

Australasian Journal of Educational Technology (C) 2014.

Please cite as: Hamid, S., Waycott, J., Kurnia, S., \& Chang, S (2014). An empirical study of lecturers' appropriation of social technologies for higher education. Australasian Journal of Educational Technology, 30(3), 295-311. 